\title{
Meningitis por Listeria monocytogenes en niñas inmunocompetentes: queso no pasteurizado como probable causa de infección
}

\author{
María del C. Valdivia-Tapia, Elizabeth Pinelo-Chumbe y Nilton Y. Carreazo
}

\footnotetext{
Hospital de Emergencias Pediátricas. Lima, Perú. Servicio de Pediatría (MVT, EPC). Servicio de Cuidados Intensivos Pediátricos (NC)

Universidad Peruana de Ciencias Aplicadas. Lima, Perú Escuela de Medicina (NC)

Recibido: 8 de enero de 2015 Aceptado: 2 de junio de 2015

Correspondencia a: Nilton Y. Carreazo yhuroc@gmail.com
}

\section{Listeria monocytogenes meningitis in immunocompetent children: unpasteurized cheese likely cause of infection}

Listeria meningoencephalitis is a rare condition, occurring mainly in immunocompromised patients. We present two cases of Listeria monocytogenes meningoencephalitis in immunocompetent children, with successful treatment with betalactam/aminoglycoside combination. Unpasteurized cheese was postulated as the source of infection.

Key words: Meningitis, Listeria, immunocompetence, cheese, food microbiology.

Palabras clave: Meningitis, Listeria, inmunocompetencia, queso, microbiología de alimentos.

\section{Introducción}

L a meningitis por Listeria monocytogenes es poco frecuente después del período neonatal, siendo principalmente asociada a pacientes inmunocomprometidos. En la última década se ha observado un aumento en su prevalencia, sobre todo en países de la Unión Europea ${ }^{1}$. A continuación, se presentan dos casos de niñas de 11 meses y 4 años, inmunocompetentes, con meningitis por L. monocytogenes.

\section{Caso 1}

Lactante de sexo femenino, de 11 meses de edad, sin antecedentes mórbidos de importancia. Consultó por un cuadro de cinco días de evolución caracterizado por fiebre, diarrea y vómitos. Sin alteraciones significativas en el examen físico inicial. El sedimento de orina y hemograma resultaron normales; la PCR de 1,6 mg/dl y látex para rotavirus fue positivo. Fue internada por intolerancia oral.

Al tercer día de hospitalización persistió con vómitos y fiebre agregándose somnolencia. Se detectó una fontanela pulsátil por lo que se realizó una punción lumbar. El estudio citoquímico del LCR tenía 2.500 cél (polimorfonucleares 70\%); glucosa $38 \mathrm{mg} / \mathrm{dl}$; y proteínas $82 \mathrm{mg} / \mathrm{dl}$, sin observarse microorganismos en la tinción de Gram. Se diagnosticó una meningitis bacteriana y se inició tratamiento antimicrobiano con ceftriaxona ( $100 \mathrm{mg} / \mathrm{kg} / \mathrm{día})$.

La paciente persistió febril, sin mejoría clínica significativa. Al sexto día de hospitalización se realizó una nueva punción lumbar con 450 células (80\% mononucleares), glucosa $54 \mathrm{mg} / \mathrm{dl}$, proteínas $110 \mathrm{mg} / \mathrm{dl}$. Nuevamente no se observaron bacterias en el Gram. Se identificó virus de Epstein Barr (VEB) en LCR por reacción de polimerasa en cadena (RPC) cualitativa. Se realizó una tomografía espiral multi-corte cerebral en la que se evidenció la presencia de un higroma laminar fronto-parieto-temporal bilateral.

El noveno día de hospitalización, se observó crecimiento de L. monocytogenes en el cultivo del LCR por lo que se agregó ampicilina ( $400 \mathrm{mg} / \mathrm{kg} /$ día) al tratamiento. La paciente continúo con fiebre, por lo que el día dieciséis de hospitalización se agregó amikacina (15 mg/kg/día).

Se realizó estudio inmunológico con medición de concentraciones de inmunoglobulinas séricas encontrándose dentro de rangos normales. (Ig M: $191 \mathrm{mg} / \mathrm{dl}$, Ig G: 1.195 $\mathrm{mg} / \mathrm{dl}$, Ig A: $62 \mathrm{mg} / \mathrm{dl}$ ). La serología para el virus de la inmunodeficiencia humana (VIH) fue negativa.

La evolución posterior fue favorable, cedió la fiebre, buena tolerancia oral y mejoró el estado de conciencia. Fue dada de alta tras 32 días de internación.

Ante la identificación de L. monocytogenes, se realizó una investigación epidemiológica en la cual se detectó que la menor consumía de forma frecuente queso no pasteurizado. Se solicitó a los padres muestras de los quesos de los centros donde habitualmente compraban el producto, identificándose el microorganismo en una de las muestras, procesada por un laboratorio privado externo. Los resultados fueron confirmados posteriormente por nuestro Laboratorio de Referencia Nacional (Instituto Nacional de Salud de Perú).

\section{Caso 2}

Preescolar de sexo femenino, de 4 años 11 meses, sin antecedentes de importancia. Ingresó por una historia de siete días de evolución caracterizado por fiebre, vómitos explosivos, cefalea y progresivo compromiso de conciencia. Cinco días antes de su ingreso a nuestro hospital 
había sido evaluada en un centro de salud privado, por fiebre y signos meníngeos. De los exámenes de laboratorio destacaba una leucocitosis con desviación izquierda, PCR $48 \mathrm{mg} / \mathrm{dl}$ y citoquímico de LCR con 1.300 leucocitos (80\% polimorfonucleares), glucosa $13 \mathrm{mg} / \mathrm{dl}$, proteínas $300 \mathrm{mg} / \mathrm{dl}$. Fue admitida en dicho establecimiento con el diagnóstico de meningitis bacteriana, por lo que recibió tratamiento antibacteriano empírico con ceftriaxona (100 $\mathrm{mg} / \mathrm{kg} /$ día). Dos días después, ante persistencia de la fiebre, se cambió esquema antimicrobiano a cefotaxima y vancomicina. Se realizó una tomografía helicoidal cerebral en la cual se observó una dilatación ventricular.

La paciente evolucionó desfavorablemente: perdió el control de esfínteres y no lograba comunicación con el entorno, por lo cual fue referida a nuestra institución. En el examen físico de ingreso se encontraba febril, con signos meníngeos presentes. Se continuó tratamiento con ceftriaxona-vancomicina. En el segundo día de internación se realizó una nueva tomografía espiral multicorte cerebral, evidenciándose una hidrocefalia hipertensiva, por lo cual se instaló un sistema de derivación ventricular externo (DVE). La paciente tuvo una evolución clínica estacionaria, con estudios seriados de LCR que mostraron mejoría (disminución de la pleocitosis y proteinorraquia). Los resultados de la tinción en LCR para Criptococcus y las sero-aglutinaciones tíficas, paratíficas y de Brucella fueron negativas. En el cuarto día se recibieron los resultados de los cultivos, aislándose L. monocytogenes en los hemocultivos y cultivo de LCR. Se cambió terapia antibacteriano a ampicilina (400 mg/kg/día) y gentamicina (7,5 mg/ $\mathrm{kg} /$ día).

La determinación de la adenosin-deaminasa (ADA) en LCR fue de $55 \mathrm{U} / \mathrm{L}$ (valor referencial $<45 \mathrm{U} / \mathrm{L}$ ). Los resultados de la RPC para Mycobacterium tuberculosis en LCR, la tinción de Ziehl Neelsen de aspirado gástrico, y un último control de ADA en LCR fue negativo (2,5 U/L).

Se realizaron estudios de inmunidad determinando las concentraciones de inmunoglobulinas séricas, las que se encontraron dentro de los parámetros normales (Ig E: 17 mg/dl, Ig A: $111 \mathrm{mg} / \mathrm{dl}$, Ig G: $922 \mathrm{mg} / \mathrm{dl}$, IgM: $122 \mathrm{mg} /$ dl). La serología para VIH fue negativa.

La evolución posterior fue lentamente favorable, evidenciándose secuelas neurológicas como déficit motor y trastorno del habla. Fue dada de alta a los 39 días de internación. No se pudo identificar la fuente directa de la enfermedad aunque en la investigación epidemiológica se descubrió que la familia se dedicaba a la fabricación artesanal de quesos y yogurt y que la menor los consumía de forma frecuente. No se pudieron analizar estos productos lácteos en búsqueda del microorganismo.

\section{Discusión}

Listeria monocytogenes es una causa infrecuente de meningoencefalitis bacteriana en niños, siendo su mayor incidencia en recién nacidos, ancianos, mujeres embarazadas y pacientes inmunocomprometidos ${ }^{2}$. Nuestros pacientes no pertenecían a los grupos etarios mencionados y los estudios realizados de inmunidad humoral fueron normales.

La meningoencefalitis por L. monocytogenes puede presentarse con manifestaciones clínicas moderadas o de forma fulminante, pudiendo llegar al coma. La fiebre es prácticamente una constante en todos los pacientes (91-100\%) y persiste más allá de una semana en $21 \%$ de los casos a pesar del tratamiento adecuado ${ }^{1}$. La presencia de cefalea y signos meníngeos es variable; es frecuente la disminución del nivel de conciencia y la presencia de signos neurológicos focales. En los pacientes mencionados se identificaron fiebre, signos meníngeos, cefalea y disminución de nivel de conciencia como datos clínicos relevantes.

Los estudios de laboratorio iniciales no revelaron algún dato específico. Con frecuencia la meningoencefalitis por L. monocytogenes se acompaña de leucocitosis ${ }^{3}$. El LCR generalmente es purulento con un recuento leucocitario de 100 a 10.000 céls $/ \mathrm{mm}^{3}$ con predominio polimorfonuclear y proteinorraquia; en $60 \%$ de los casos la glucorraquia es normal. Los hemocultivos son positivos en 60 a $75 \%$ de los casos. La tinción de Gram en el LCR puede mostrar cocobacilos grampositivos, orientando el tratamiento empírico inicial contra este agente, aunque éstos puedan confundirse fácilmente con otros microorganismos. Dada la baja sensibilidad de la tinción para esta bacteria (0-40\%) en ocasiones puede ser negativa ${ }^{3}$. Nuestros pacientes tenían leucocitosis, y en el LCR, pleocitosis con hipoglucorraquia e hiperproteinorraquia. La tinción de Gram fue negativa y se pudo aislar el microorganismo en el LCR en el primer caso y en LCR y sangre en el segundo caso.

En la literatura científica se han reportado casos de co-infección de L. monocytogenes con diversos microorganismos, como el virus de la hepatitis $\mathrm{A}^{4}$, sarampión ${ }^{5}$, varicela, $N$. meningitidis y el VEB. Estos últimos muestran tropismo marcado por el sistema inmunitario y pueden producir inmunosupresión por afectación transitoria de la inmunidad celular a través de efectos inhibidores sobre la producción de citoquinas secretadas por los monocitos/ macrófagos activados. En consecuencia, ante un caso de meningoencefalitis por L. monocytogenes en un niño con un sistema inmunitario aparentemente normal, es necesario investigar la posible co-existencia de un agente viral que pueda originar una inmunodeficiencia transitoria. Tal y como sucede en nuestro primer caso, en el cual se pudo identificar la presencia de una infección por VEB. No efectuamos evaluación de su inmunidad celular, sólo descartamos la presencia de infección por VIH.

La importancia de considerar a L. monocytogenes como etiología de meningitis radica en su falta de respuesta a las cefalosporinas de tercera generación, actualmente el 
tratamiento antibacteriano empírico más extendido para las meningitis bacterianas no neonatales 6 . Por lo tanto, es preciso considerar este microorganismo en aquellas meningitis supuradas sin presencia de microorganismos en la tinción de Gram que, recibiendo tratamiento empírico, presenten una evolución clínica desfavorable, hidrocefalia y/o continuo deterioro neurológico; aun en pacientes inmunocompetentes ${ }^{7}$. De la misma manera, debido a la prevalencia de la enfermedad por micobacterias en países en desarrollo, es pertinente considerar como diagnóstico diferencial la meningitis por $L$. monocytogenes ante la sospecha de meningoencefalitis tuberculosa; puesto que tanto la presentación clínica (fiebre, alteración en los niveles de conciencia, hiporexia, vómitos, cefalea, síndromes meníngeos e hipertensión endocraneal), como los exámenes de laboratorio (LCR con leucorraquia, hipoglucorraquia, proteinorraquia e incluso falsos positivos del ADA) e imágenes tomográficas suelen ser similares en ambas entidades ${ }^{8}$.

El tratamiento de elección para la listeriosis es ampicilina asociada con aminoglucósidos (gentamicina o amikacina $)^{6,9}$. En ambos casos presentados, se observó una buena respuesta clínica a la administración de esta asociación.

Entre las complicaciones más frecuentes en pacientes con meningoencefalitis por Listeria spp. se encuentra la hidrocefalia aguda no comunicante, como en el caso de la segunda paciente que requirió la colocación de una DVE. Asimismo se han asociado secuelas neurológicas en 13 a $16 \%$ de los casos con meningoencefalitis por $L$. monocytogenes ${ }^{7}$, tal y como evolucionó el segundo caso descrito.

Los principales reservorios de L. monocytogenes son el suelo, el forraje, el agua, los silos y el tracto gastrointestinal de aves, peces y mamíferos incluyendo el ser humano. La infección se adquiere generalmente mediante la ingesta de alimentos contaminados: carne, pescado, vegetales crudos y productos lácteos no pasteurizados ${ }^{10}$. En ambos casos presentados, se comprobó la historia de consumo frecuente de lácteos no pasteurizados, siendo aislado inclusive el microorganismo en uno de ellos.

\section{Resumen}

La meningoencefalitis por Listeria spp. es una infección infrecuente, principalmente en pacientes con algún tipo de inmunosupresión. Presentamos dos casos clínicos de meningitis por Listeria monocytogenes en niñas inmunocompetentes con tratamiento exitoso con $\beta$ lactámicos combinados con aminoglucósidos; se identificó la ingesta de queso no pasteurizado como probable fuente de infección.

\section{Referencias bibliográficas}

1.- Allerberger F, Wagner M. Listeriosis: a resurgent food borne infection. Clin Microbiol Infect 2010; 16: 16-23.

2.- Ávila A, Lezerovich D, Sabio-Paz V, Lenz M, Chede C, Varón J, et al. Meningitis de etiología poco habitual en niños. Arch Argent Pediatr 2004; 102; 208-10.

3.- Posfay-Barbe K M, Wald E R. Listeriosis. Pediatr Rev 2004; 25: 151-9.

4.- Boga A S, Montero R B, García F S, Valcárcel G R. Listeria monocytogenes meningitis during the incubation period of hepatitis A disease. Pediatr
Infect Dis J 2000; 19: 265-6.

5.- Arrevillaga B G, Gómez G B. Aspectos moleculares de coinfecciones de virus respiratorios con bacterias. Enf Inf Microbiol 2006; 26: 115-22.

6.- Elder C J, Urquhart D S. Limitations of empirical therapy for bacterial meningitis in a healthy child with Listeria monocytogenes meningitis. J Pediatr Neurol 2006; 4: 65-7.

7.- Platnaris A, Hatzimichael A, KtenidouKartali S, Kontoyiannides K, Kollios K, Anagnostopoulos J, et al. A case of Listeria meningoencephalitis complicated by hydrocephalus in an inmunocompetent infant.
Eur J Pediatr 2009; 168: 343-6.

8.- Guillen D, Campos P, Hernández H, Chaparro E. Meningoencefalitis tuberculosa en niños: diez años de experiencia en el Hospital Nacional Cayetano Heredia. Rev Med Hered 1993; 4 : 182-7.

9.- Sánchez B, Palencia E. Infecciones por Listeria. Medicine 2010; 10: 3368-72.

10.- Peer M A, Nasir R A, Kakru D K, Fomda B A, Wani M A, Hakeem Q N. Listeria monocytogenes meningoencephalitis in an immunocompetent, previously healthy 20-month old female child. Indian J Med Microbiol 2010; 28: 169-71. 